\title{
A Textual Research on the Spread of the San Zi Jing in the Cultural Circle of Foreign Chinese Characters and its Value in the Foreign Chinese Character Teaching
}

\author{
Kang Xiaoming ${ }^{1,}$, , Lian Jing ${ }^{2}$, ${ }^{*}$ \\ ${ }^{1}$ College of Chinese Language and Literature, Northwest Normal University, Lanzhou, Gansu, China \\ ${ }^{2}$ College of Foreign Language and Literature, Northwest Normal University, Lanzhou, Gansu, China \\ a Kangxm1370105705@163.com \\ b*lj885046039@163.com
}

\begin{abstract}
San Zi Jing has been widely spread in the cultural circle of foreign Chinese characters as an enlightening reading material for memorizing Chinese characters, but today, with the rapid development of international Chinese education, it seems to be powerless. This paper combs the time limit and influence of the spread of San Zi Jing in Korean Peninsula, Japan and Vietnam, and takes San Zi Jing Zhu published by Zhao Xingnan in Ming Dynasty as an example. This paper makes statistics on the number and proportion of first -, second-and third-level Chinese characters in The Graded Chinese Character Table for Chinese International Education, explains its role in memorizing Chinese characters, and emphasizes its value in foreign Chinese character teaching.
\end{abstract}

Keywords: San Zi Jing; cultural circle of foreign Chinese characters; foreign Chinese character teaching; value

\section{《三字经》在域外汉字文化圈传播考及在对外汉字教学 中的价值}

康小明 ${ }^{1,}{ }^{2}$ 廉静 ${ }^{2, b *}$

1 西北师范大学文学院, 兰州, 甘肃, 中国

2 西北师范大学外国语学院, 兰州, 甘肃, 中国

${ }^{a}$ Kangxm1370105705@163.com

b*lj885046039@163.com

\section{摘要}

幼学蒙童典籍《三字经》曾在域外汉字文化圈作为识记汉字的启蒙读物广为流传, 但至国际中文教育迅猛发展 的今天, 其似乎威无所施。本文梳理了《三字经》在朝鲜半岛、日本及越南的传播时限及其影响，并以明刻赵 星南版《三字经注》为例, 统计了其在《汉语国际教育用分级汉字表》中一级、二级、三级汉字的数量及占比, 阐释了其在识记汉字方面的作用，强调其在对外汉字教学中的价值。

关键词：三字经；域外汉字文化啳；对外汉字教学；价值 


\section{1.引言}

1971 年日本语言学家藤堂明保在其著作《汉字 とその文化圈》中，首次提出了 “汉字文化圈” 这一 概念, 并详细剖析总结了汉字文化圈的形成及其发 展。所谓汉字文化圈是指: 以中国大陆为主体, 以中 印半岛东侧、朝鲜半岛为两翼, 日本列岛等地为外缘, 以汉字为信息载体的人文地理区域 ${ }^{[1]}$, 其包括汉字、 儒学、律令和中国化的佛教四项文化要素 ${ }^{[2]}$, 而汉字 则是汉字文化圈存在的先决条件 ${ }^{[3]}$, 因此, 对域外汉 字文化圈的国家来说，汉字启蒙教育是十分重要的。

“三、百、千、千”（《三字经》《百家姓》《千字文》 《千家诗》) 作为中国古代蒙学经典, 对域外汉字文 化圈汉字蒙童教育发挥了重要作用。而被誉为 “蒙学 之冠” “袖里通鉴纲目” “千古一奇书” “小型百 科全书” 等的《三字经》尤为重要。但至今日, 在 “汉 语热” 背景下, 在国际中文教育迅猛发展的今天, 《三 字经》似被遗忘, 其识记汉字的作用威无所施。因此, 梳理《三字经》在古代域外汉字文化圈的传播及影响, 并阐释其在识记汉字方面的作用, 挖掘其在当代对外 汉字教学中的价值, 是很有意义的。

\section{2.《三字经》在域外汉字文化圈的传播}

\section{1《三字经》在朝鲜半岛的传播}

朝鲜半岛现存最早的《三字经》, 是韩国忠南大 学图书馆所藏的《新刊三字经》, 该书文末附有 “万 历岁丁末年冬, 玄览堂梓《新刊三字经》终”一行字, “万历岁丁末年” 为 “万历三十五年” ，也即 1607 年, 钱茂伟 ${ }^{[4]}$ 指出, 该时间点离我国首次出现《三字 经》记录的正德三年 (1508 年) 正好 100 年, 又因 为有 “新刊” 二字, 所以可以肯定该书并不是《三字 经》在朝鲜半岛最早的版本。而崇祯十六年 (1643 年), 朝鲜半岛出现了自己抄写并略加删改的《新刊 三字经》, 此后《三字经注解》《增注三字经》等也相 继问世。刘春兰 ${ }^{[5]}$ 认为, 在 “李氏王朝” 统治朝鲜半 岛时期, 地方乡学、民间书院和私学书院大量使用来 自中国的童蒙课本。韩国白石大学闵庚三 ${ }^{[6]}$ 指出：孩 童读书也像中国一样, 始于《三字经》等汉文启蒙读 物, 随后研读《四书》《五经》等儒家经典。而民间 书院和私学书院是 16 世纪以后在国家的奖励下才开 始在朝鲜半岛普及, 而此时民间书院和私学书院已经 使用《三字经》作为汉文启蒙读物, 但外来典籍从引 介到普及是要经历时间检验的, 因此《三字经》在朝 鲜半岛的流传应在 16 世纪左右。

\section{2 《三字经》在日本的传播}

据史料记载, 日本进入江户时代后（1603-1868 年), 有关《三字经》的记载开始出现并增多。在大 庭修所著之《江户时代中国文化受容研究》中附有 “唐船持渡书籍目录”, 其中便有 “西五号唐船作为
日本贩卖之物, 携《三字经》二百九十六部各一种” 的记录。而在永禄五年（1692 年）发刊的《广益书 籍目录》中, 已经列有《三字经》和 《三字经注解》 ${ }^{[7]}$ 。这表明在江户时代初期，《三字经》便已在日本 流传, 成为较有影响力的汉字蒙学典籍。江户末期至 明治初年，《三字经》在日本进一步传播并涌现出了 不少衍生自《三字经》的作品, 鹤岛俊一郎、董明 ${ }^{[8]}$ 指出, 日本《三字经》仿制本约 20 种, 其中较为出 名的有《本朝三字经》《皇朝三字经》《日本三字经》 《皇朝新三字经》等作品。值得一提的是, 日本教育 学家石川谦 ${ }^{[9]}$ 指出, 日本永和三年 (1377 年) 出版的 儿童启蒙读物《童子教》中出现了如下文字: 苏秦为 学文, 雉刺股不眠。俊敬为学文, 头悬梁不眠。车胤 好夜学, 聚茧为灯矣。宣士好夜学, 积雪为灯矣。此 等人者皆, 昼夜好学文。上述文字很可能是受《三字 经》中 “头悬梁, 雉刺股, 彼不教, 自勤苦。如囊萤, 如映雪, 家虽贫, 学不辍” 等字句影响而成的 ${ }^{[10]}$ 。如 若这一推论成立的话，《三字经》在日本的传播将被 大大提前, 当然该推论还需更多的材料支撑。

\section{3 《三字经》在越南的传播}

《三字经》在越南的传播情况相较于朝鲜半岛和 日本又有所不同, 由于秦汉至宋初, 越南一直是我国 历代封建王朝的行政区划, 我国史学家将该历史阶段 称为 “千年郡县时期” ，越南称之为 “北属时代”。 即使越南实现封建自主后, 越南历代王朝仍与我国保 持着 “藩属” 关系并维系其关系直到 1885 年中法签 订《天津条约》之后 ${ }^{[11]}$ 。因此, 越南对汉字的态度相 较于朝鲜和日本更为主动, 直至二战后, 汉字在越南 才逐渐罕用。越南现存最早的《三字经》版本是藏于 越南汉喃研究院图书馆的《三字经解音演歌》, “该

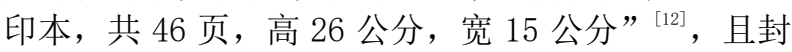
面上写着 “明命十七年新镌” ，即 1836 年再版, 因 此第一版《三字经》肯定要早于 1836 年。此外, 阮 俊强 ${ }^{[13]}$ 找到的有关《三字经》的最早记载是越南阮朝 范望于嗣德六年（1853 年）在《启童说约自序》写 到: 余童年, 先君子从俗命之, 先读《三字经》及三 皇诸史, 次则读经传, 习时举业文字, 求合场规, 取 青紫而已。虽然作者范望的生卒年均不详, 但根据

“河内国家图书馆书号 R. 562, 木刻”可知他于 1841 年中举。再结合 “十年灯火” 的固有观念, 范望应于 1830 年开始接受 “大学” 教育, 因此, 阮俊强将 1830 年视为《三字经》传入越南的可信年代 ${ }^{[13]}$ 。但事实上, 在 “大学” 教育之前, 还要经历 “小学” 的蒙学教 育, “八岁左右的 “幼童” 进入 “小学” 接受蒙学教 育, 而十五岁以上的 “成童” 则进入 “大学” 接受成 童教育” [14]。因此, 我们可以将阮俊强的结论再往前 至少推七年, 即最晚 1824 年, 《三字经》已成为越南 蒙学教育的经典。

与日本相仿, 越南也出现了大量衍生自《三字经》 的作品, 如: 《女训三字经》《大越三字史记》《蒙学 越史三字教科书》, 此外, 还出现了《三字经》的喃 
文注本, 如《三字经国音哥》《三字经撮要》等, 其 中制科榜眼武惟清于辛亥年 (1851 年) 演音并注解《三 字经撮要》, 因参考理学、文法简易、义理详明、内 容丰富而成为《三字经》喃文注本的代表。

综上所述, 作为中国古代蒙学经典的《三字经》 对域外汉字文化圈蒙童识记汉字和域外汉字文化圈 的形成发挥了巨大的作用, 其传播范围之广、通行时 间之长、影响之深远空前绝后 ${ }^{[15]}$ 。

\section{3. 《三字经》在对外汉字教学中的价值}

《三字经》的宋元刻本未见留存, 因此无法知其 确切字数, 但自明代以降《三字经》因版本的不同, 字数也略有差异。不论是明末版《三字经》(1122 字), 还是流传最广的清道光版《三字经》(1140 字), 均 是以现存最早的明刻赵星南版《三字经注》(1086 字) 为原本增补而来的 ${ }^{[16]}$ 。因此, 我们以该版本为准, 阐 释其在识记汉字方面的作用, 强调其在对外汉字教学 中的价值。

千禧年后, “汉语热”现象持续升温, 国际中文 教育事业进入了新阶段, 但因为平面型表意的方块汉 字和线性表音的拼音文字在文字形体、语音规则及语 义透明度方面差异极大, 因而导致对外汉字教学一直 是国际中文教育的短板, 非汉语母语者都不同程度地 存在 “过汉字关” 的问题。为了进一步弥补该短板, 中国教育部、国家语言文字工作委员会于 2010 年发 布了《汉语国际教育用音节汉字词汇等级划分》。该 规范中的《汉语国际教育用分级汉字表》将汉语国际 教育用汉字分为 “一级” “二级” 和 “三级” , 分别 对应汉语二语水平为 “初级” “中级” 和 “高级” 的学习者应掌握的汉字, 其中 “一级” “二级” 各有 900 个汉字, “三级” 共计 1200 个汉字, 此 3000 个 汉字均为现代汉语常用字。而明刻赵星南版《三字经 注》共 1086 字, 仅有 518 个非重复汉字, 对比《现 代汉语常用字表》 (国家语言文字工作委员会汉字处 编, 1988), 发现这 518 字中共有 475 个现代汉语常 用字，占比高达 $91.70 \%$ 。

将这 475 个字与《汉语国际教育用分级汉字表》 相对照, 发现其汉字等级分布及数量分别为一级汉字 296 个、二级汉字 98 个、三级汉字 81 个, 占此 475 字之比分别为 $62.32 \% 、 20.63 \%, 17.05 \%$ ；占《汉语国 际教育用分级汉字表》总汉字量的 $15.83 \%$, 占其一 级、二级、三级汉字之比分别为 $32.89 \% 、 10.89 \%$ 、 $6.75 \%$ 。又因为后世各版 《三字经》均是在明刻赵星 南版《三字经注》的基础上增补而成的, 且各版本《三 字经》均成书于近代汉语时期, 文中某个汉字的字 形、读音、意义及用法和现代汉语中该汉字的差别较 小或完全相同。所以说掌握了任何一版《三字经》中 的汉字就意味着至少掌握了《汉语国际教育用分级汉 字表》中 $15.83 \%$ 的汉字, 同时也至少掌握了 $32.89 \%$ 的一级汉字、 $10.89 \%$ 的二级汉字及 $6.75 \%$ 的三级汉字。

现代汉语常用字中处于核心地位的是几百个简
单的书写符号, 正如高本汉 ${ }^{[17]}$ 所说: “一旦你学会了 这几百个简单的书写符号, 即基本材料, 那就只是个 拼字问题了，“手” 和 ‘口’ 两个成素结合起来就造 成了 “扣” 字等等”。事实上 《三字经》中恰恰又包 含了大量这种 “简单的书写符号” 及其变体 (如 “人

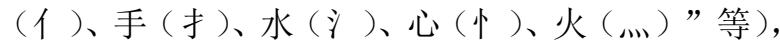
由这些 “简单的书写符号” 及其变体, 我们可以使汉 语二语习得者习得更多 “复杂的书写符号” , 即掌握 更多复杂的汉字。根据 2007 年中国语言生活状况报 告: 基于 10.07 亿汉字的语料, 发现 964 个汉字的 文本覆盖率高达 $90 \%$, 此外, 现代汉语构词法以复合 构词为主, 而《三字经》中有大量的成词语素, 这些 成词语素的形音义稳定, 经常用作词根并两两组合构 成新词。梁永国 ${ }^{[18]}$ 指出 “ 3736 个字可构成四万五千 多个词, 占现代汉语总词数的 $90 \%$ 左右, 4990 个字则 构成了《现代汉语词典》几乎所有的词”。因此, 《三 字经》中 475 个现代汉语常用字的构词数量也是相当 客观的。

此外, 《三字经》在形式上和内容上极具特色, 在形式上 “三字一句, 韵律和谐” ; 在内容上 “综合 性强, 涵盖面广”。前者表现为: 《三字经》全文三 字一句, 四句一韵, 如 “人之初, 性本善。性相近, 习相远。荷不教, 性乃迁。教之道, 贵以专。” 韵脚 字都落在偶数句的最后一字, 节奏整齐, 韵律和谐, 琅琅上口, 极具音乐之美。该特点能够化无声的文字 为有声的语言, 使得汉语二语习得者不但能注意汉字 的书写, 更能注意汉字的读音。后者表现为: 《三字 经》涵盖的知识面很广, 内容十分丰富, 既涵盖了教 育、伦理、道德、天文、历史、时节、地理, 又涵盖 了儒家经典和优秀人物。这一特点使得汉语二语习得 者习得汉字的同时也可以增长知识、获得启迪。

汉语二语习得者如若能够掌握任何版本《三字 经》中的现代汉语常用字则意味着至少掌握了《汉语 国际教育用分级汉字表》中 15. 83\%的汉字、32.89\% 的一级汉字、10.89\%的二级汉字、6.75\%的三级汉字; 其次, 以《三字经》中的 “简单的书写符号” 及其变 体为 “钥匙” 可以解锁更多现代汉语常用字, 也即会 解锁更多的 “一级” “二级” “三级” 汉字; 再次, 以《三字经》中的成词语素为媒介, 便可掌握更多的 复合词; 最后, 《三字经》不但可使汉语二语者注意 汉字书写的同时注意汉字的读音, 更能增长知识、获 得启迪。由此可见, 作为 “蒙学之冠” 的《三字经》 在当代外对汉字教学中仍大有可为。

\section{4. 结语}

综上所述, 《三字经》作为古代中国蒙学经典, 通过在朝鲜半岛、日本列岛及越南的传播及在蒙学教 育中的普及, 为域外汉字文化圈的形成打下了坚实的 基础。而在当今世界, 尤其是在国际中文教育持续升 温的今天, 我们应该重新审视《三字经》在识记汉字 方面的作用, 深入挖掘其在对外汉字教学中的价值, 消弭对外汉字教学的短板, 打破西方汉学家眼中汉字 
是封闭中国文化长城的观点, 向世界展示汉字魅力, 讲好汉字故事。

\section{REFERENCES}

[1] Feng, T.Y. (2004) Some Comments on the Chinese-Character Cultural Circle. Journal of Jishou University Social Science,2:1-6.

[2] Li, X. S., Chen, S. S. (2002) Five thousand years history of the cultural exchanges between China and foreign countries (Vol.1). World Affairs Press, Beijing.

[3] Lin, L. F. (2006) On the Culture Circle of Chinese Characters in East Asia and Its Forming. Crossroads: Southeast Asian Studies, 8: 58-62.

[4] Qian, M.W. (2009) Studying on exlitions of San Zi Jing found in Korean. Documents,4:162-166.

[5] Liu, C.L. (2011) The Research Review of Chinese Textbooks in the Korean Era. Chinese Language Learning,2:98-105.

[6] Min, G.S. (2013) The Past, Present and Future of Korean Classics Reading Education. Journal of Chinese Education,1:221-228.

[7] Xu, R., Lu, L. (2009) A Brief Discussion on the Spread of San Zi Jing in Domestic and Overseas. Journal of Tianzhong,24:128-130.

[8] Turusima, S., Dong, M. (2004) Popularity of San Zi Jing in Japan and Japanese San Zi Jing. Journal of Beijing Normal University (Social Science),4:123-125.

[9] Shi, C.Q., Tong, Z.J. (1967) Japanese Textbooks Series -Intercourse Compile. Jiang Tan Press, Tokyo.

[10] Tan, J.C. (2010) San Zi Jing: Its Spread and Development in Japan. Journal of Southwest University (Social Sciences Edition),36:71-74.

[11] Liang, M.H. (2014) Brief Review on the Rising and Declining History of Chinese Characters in Vietnam. Around Southeast Asia,6:63-68.

[12] Ren, X.F., Deng, Y.L. (2020) The Dissemination and Influence of Three Character Classic in Vietnam. International Sinology,2: 150-154+204-205.

[13] Ruan, J.Q. (2015) Acceptance, Adaptation and Innovation: A Textual Research on the San Zi Jing in Ancient Vietnam. Sinographic Texts and Cultures, Beijing.

[14] Zhu, Z.H. (2016) The Primer Tradition and Reflections on Chinese Education over the Past 100 Years. Theoretical Studies in Literature and
Art,36:148-155.

[15] Ren, X. F., Zhang, J., Chen, D. L., Liu, Y. J. (2019) Studies on the Overseas Dissemination of Chinese Ancient Primer Classics. Journal of Jiangsu University (Social Science Edition), 21: 64-71.

[16] Lu, L. (1994) San Zi Jing Journal. Anhui Education Press, Hefei.

[17] Karlgren, B. (2017) The Chinese Language: An Essay on Its Nature and History. The Commercial Press, Beijing.

[18] Liang, Y.G. (2005) Scientificity and Simplicity of Modern Chinese Character System. Modern Chinese, 8 : 10-11+26.

[19] Da, T.X. (1984) Study on Acceptance of Chinese Culture in Edo Period. Tong Peng Press, Tokyo.

[20] Chinese Characters Department of State Language Commission. (1988) The Table of Commonly-used Chinese Characters. Chinese Press, Beijing. 